\title{
Editorial: 50 Years of High Impact Research
}

The first issue of Metallurgical Transactions appeared in 1970, with Gerhard Derge of the Carnegie Institute of Technology as Editor. The journal formed as a result of the merger of Transactions of the Metallurgical Society of AIME and Transactions Quarterly of the American Society for Metals. In 1975, the journal split into Metallurgical Transactions $A$ and $B$, specializing in physical and process metallurgy, respectively. The journals were renamed Metallurgical and Materials Transactions (MMT) $A$ and $B$ in 1994. The non-profit MMT journals are jointly managed by TMS and ASM and support a broad range of professional activities within the societies. MMT serves the entire international community, with broad geographical representation on the editorial board.

It is interesting to consider the 10 most highly cited papers of 1970, which will be familiar to many:

- Dispersion Strengthened Superalloys by Mechanical Alloying, J.S. Benjamin, https://rd.springer.com/article/10. 1007/BF03037835

- The Relation Between Polycrystal Deformation and Single-Crystal Deformation, U.F. Kocks, https://rd.springer. com/article/10.1007/BF02900224

- The Effect of Carbide and Nitride Additions on the Heterogeneous Nucleation Behavior of Liquid Iron, B.L. Bramfitt, https://rd.springer.com/article/10.1007/BF02642799

- The Influence of Alloying, Temperature, and Related Effects on the Stacking Fault Energy, P.C.J. Gallagher, https://rd.springer.com/article/10.1007/BF03038370

- The Temperature Dependence of the Flow Stress of the $\gamma^{\prime}$ Phase Based upon Ni $i_{3} A l$, P.H. Thornton, R.G. Davies, and T.L. Johnston, https://rd.springer.com/article/10.1007/BF02819263

- The Origin of Freckles in Unidirectionally Solidified Castings, S.M. Copley, A.F. Giamei, S.M. Johnson and M.F. Hornbecker, https://rd.springer.com/article/10.1007/BF02643435

- The Martensite Phases in 304 Stainless Steel, P.L. Mangonon and G. Thomas, https://rd.springer.com/article/10. 1007/BF02642003

- The Role of Dislocations in the Flow Stress Grain Size Relationships, J.C.M. Li and Y.T. Chou, https://rd. springer.com/article/10.1007/BF02900225

- Interdendritic Fluid Flow and Macrosegregation; Influence of Gravity, R. Mehrabian, M. Keane, and M.C. Flemings, https://rd.springer.com/article/10.1007/BF02900233

- The Role of Oxide Microstructure and Growth Stresses in the High-Temperature Scaling of Nickel, F.N. Rhines and J.S. Wolf, https://rd.springer.com/article/10.1007/BF02642020

In 2020, there is still active research on the material systems in these papers as well as on the phenomena studied, enabled by remarkable developments in instrumentation, theory, computation, and data-driven approaches. Entirely new material systems have emerged since 1970, including nanostructured materials, intermetallic compounds, metallic glasses, TRIP/TWIP steels, and high entropy alloys. Processing innovations have also been prominent, with recent examples including friction stir welding, equal channel angular extrusion, strip casting, and many variants of additive manufacturing. Atom probe tomography, electron backscattered diffraction, high-resolution scanning transmission electron microscopy, synchrotron X-ray diffraction, high temperature in situ observations, and many other instrumentation innovations have brought important new insights to material structure and properties. Advances in theory and simulation, from the atomic scale (density functional theory, molecular dynamics), to the micro-scale (dislocation dynamics, phase field, cellular automata) and the macroscale (crystal plasticity finite element analysis, fluid flow and solidification) have also revolutionized our understanding and guided us toward the new materials and processes reported each year in MMT. 
To highlight the rich scientific tradition of MMT, the editorial team has invited a series of articles from distinguished scientists on current topics of interest to the community. These articles will appear in free-access form in issues published throughout this volume year, and will be accessible at https://www.springer.com/journal/11661 (MMTA) and https://www.springer.com/journal/11663 (MMTB), within the Collections link. (The entire collection across both journals can be found at https://www.springer.com/journal/11661/updates/17852226.) The papers convey the current understanding of a wide spectrum of phenomena related to materials structure, processing, and properties, and point to important challenges for the future. The next 50 years will undoubtedly be an equally exciting time for materials, and Metallurgical and Materials Transactions will continue to evolve in scope, content, and delivery to continue to convey, with the highest standards, the emerging and ever-evolving research of this field.

Publisher's Note Springer Nature remains neutral with regard to jurisdictional claims in published maps and institutional affiliations.

Tresa M. Pollock

University of California, Santa Barbara, CA, USA e-mail: tresap@ucsb.edu

Antoine Allanore Massachusetts Institute of Technology, Cambridge, MA, USA

Amy J. Clarke Colorado School of Mines, Golden, CO, USA

Jonathan Cormier ISAE-ENSMA, Futuroscope-Chasseneuil, France

Matthias Militzer The University of British Columbia, Vancouver, BC, Canada

Jian-Feng Nie Monash University, Melbourne, Australia

Sridhar Seetharaman Colorado School of Mines, Golden, CO, USA

Il Sohn Yonsei University, Seoul, Republic of Korea 